\title{
MAJOR ISSUES OF INSIDER THREAT AND ATTACK BASED ON LESSONS LEARNED IN THE AREA OF OPERATIONS
}

\author{
Tibor HORVÁTH \\ National University of Public Service, Budapest, Hungary \\ horvathtibor@uni-nke.hu \\ József Lajos KOMJÁTHY \\ National University of Public Service, Budapest, Hungary \\ komjathy.lajos.jozsef@uni-nke.hu
}

\begin{abstract}
This article presents an overview of the insider threats appearing during peace support operations, including their types, and the risks to the stability of democratic states, which are present even in the activities of governmental forces. The authors analyse and categorise the various types and forms of threats, furthermore, they also examine expectations that arise in modern, $21^{\text {st }}$ century peace operations and armed conflicts. Finally, recommendations for the preparation for and the defence against these threats are also formulated.
\end{abstract}

KEYWORDS: asymmetric warfare, defence, peace operations, preparing, training

\section{Introduction}

Making and maintaining peace in crisis areas of the world will continue to be a major task in the $20^{\text {th }}$ century too. In addition to their complexity, such missions involve a number of challenges that can significantly affect the success of our operations, the achievement of our military and political goals. In the preparation of the assigned peacekeeping forces and the execution of missions, we are increasingly confronted with a serious, previously less significant threat: the internal threat and the various forms of its manifestations.

The timely recognition of the signs of such threats can significantly determine the success of operations. Impact-based hybrid warfare, typical for our century, already includes insider attacks as one of the potential elements of asymmetric warfare. Such threat may be more pronounced in multinational forces where multicultural circumstances are prevalent, therefore commanders and their staffs must pay special attention to avoiding, averting, and reducing the impact of internal threats. The significance of the topic is indicated by the large number of attacks that took place against the forces involved in peacekeeping operations, also highlighted by the authors' experience gained in the area of operations. Insider attacks are not limited to military 
forces, they are also aimed at other actors, such as police forces, or civilians who run a support or service infrastructure. The targets of attacks can range from representatives of international forces to local government forces.

The authors share with readers their experience in important positions in the Afghanistan (ISAF) RC-N headquarters and missions in the Balkans (SFOR, KFOR, MFOR) as well as the results of their scientific research. The planning, organization and management of the implementation of the operations has greatly contributed to the scientifically demanding research of the problem. After scientific observation made during military operations, their evaluation and conclusions, the authors arrived at these results.

According to the motto of our article: "The history of mankind is merely the history of warfare. People have always killed each other and will do so forever. Therefore, the most important characteristic of man is how much skill he can acquire in warfare. Everything else is subordinated to this" (Scarrow, 2020).

\section{Definition, Motives and Manifestations of Internal Threat and Attack}

The definition of the phenomenon of internal threat as the most important element should be the first step in discussing the topic of the article.

Internal threat, as defined by the authors, is a special type of attacks where the perpetrator belongs to the personnel of the targeted unit or facility and, as an internal person, gets close to the point of attack (target). Such attacks may no longer take place just in the areas of operation but also in the rear areas, or even in countries sending peacekeeper personnel (Horváth, 2014).

Applying the narrowed phenomenon (concept) to the military field, the following definition is proposed: An internal threat to the military comprises armed attacks against military organizations where the attacker is a member of that particular military organization or of its support personnel, and the target is the military infrastructure, especially its personnel.
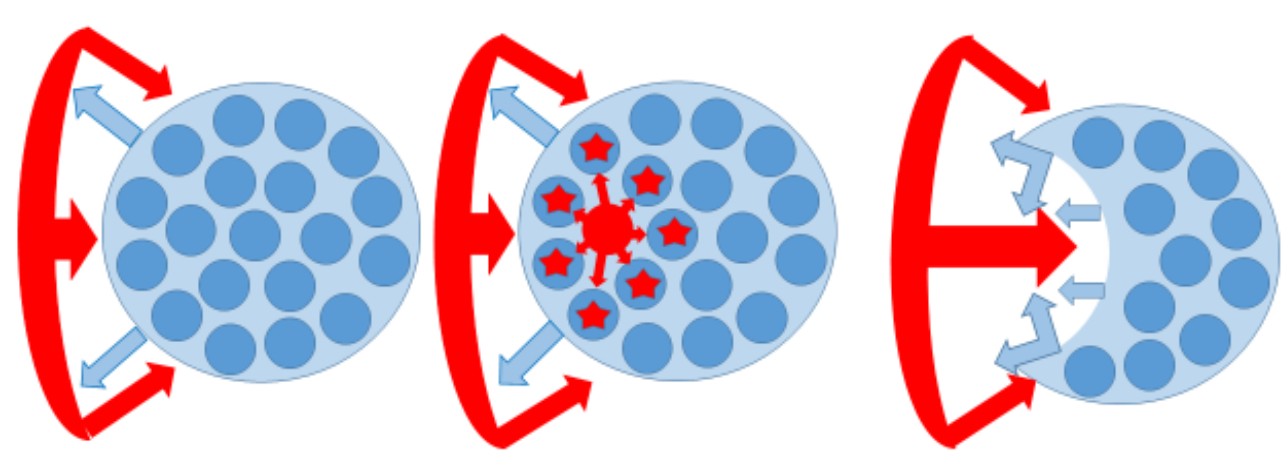

Figure no. 1: The mechanism of action of internal attacks

(Source: Authors)

In the authors' opinion, the mechanism of action of insider attacks is well presented in Figure no. 1, which illustrates the fact that such incidents are often more dangerous than external dangers and has a larger impact on friendly forces (Komjáthy, 2016). 
In peacekeeping operations, insider attacks most often take place in the stabilization phase, typically targeting the personnel of stabilization forces, persons representing the new, democratic regime, or elements of critical infrastructure, whose destruction or demolishment may generate serious difficulties in new, democratic processes and supply (This is also indicated by the annual breakdown of insider attacks, shown in Figure no. 2).

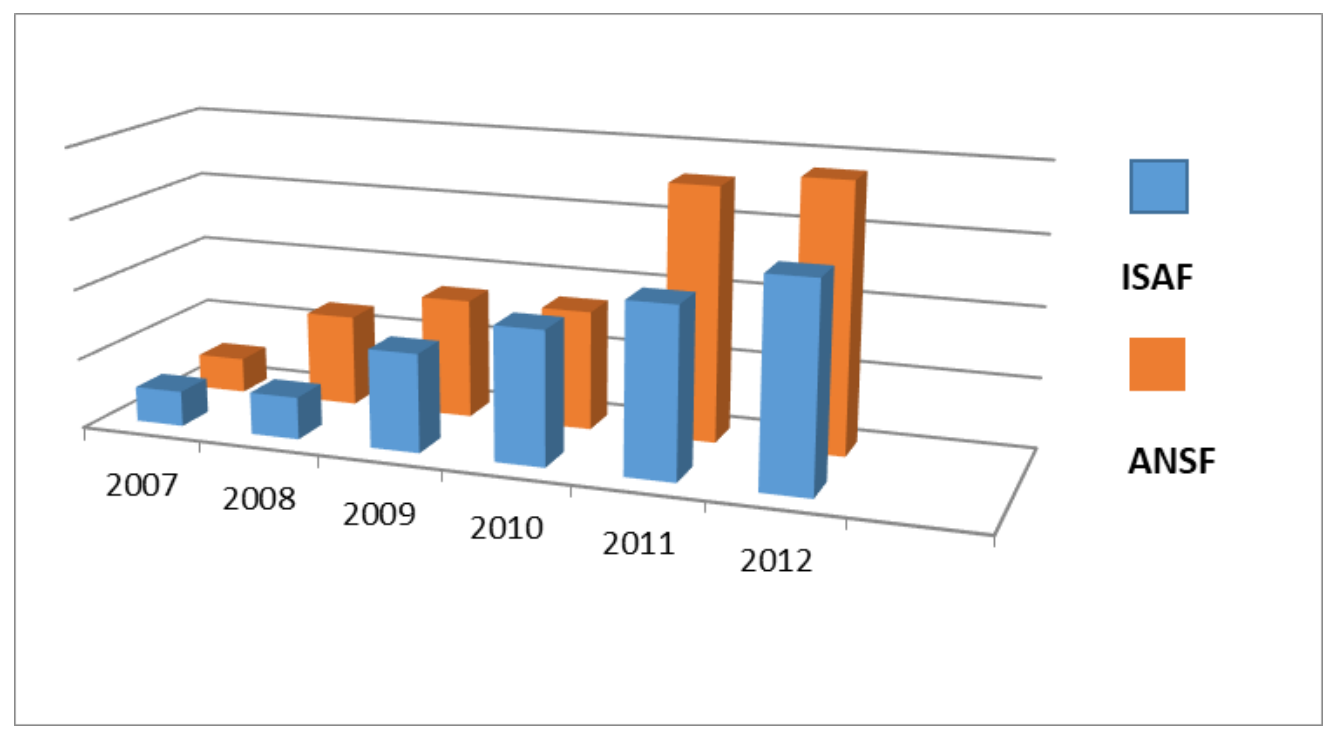

Figure no. 2: Annual numbers of internal attacks (In Afghanistan, during ISAF operations. Source: ISAF Insider Threat Handbook)

(Source: Authors)

It seems reasonable to examine the causes and patterns of attacks, among which the events related to individual grievances may be of high importance. Individual grievances can usually develop during peace operations, or during the conduct of joint tasks, missions, or training programs. The methods used by international trainers in the preparation and training of the government forces - border guards, military forces, police forces - of a young democratic state provide a large number of opportunities that can be experienced as a personal injury by a person participating in a training program (Komjáthy, 2017a). Such resentment can be a failure experience or a verbal insult during the training, a verbal insult or injury caused by the trainer, or even an activity perceived as a physical injury. It is a very important fact that age provides authority in many religious and cultural regions. Impairment or insult of authority, or even a perception of that can be an excellent cause of an inside attack. In the training system of many countries, physical contact between the trainer and the trainee is prohibited, however, there are countries where this is essential and that may generate a large number of misunderstandings. It may also be the basis of an attack carried out during training. Another motivation to execute an attack may be an important individual cause when a family member of the trainee became a victim (injured, wounded, or lost) during peace support operations.

Peacekeeping forces are often portrayed as a grievance for an entire community, in many cases even as conquerors by the local or rebel media, and as oppressors of the identity and culture of the community. 


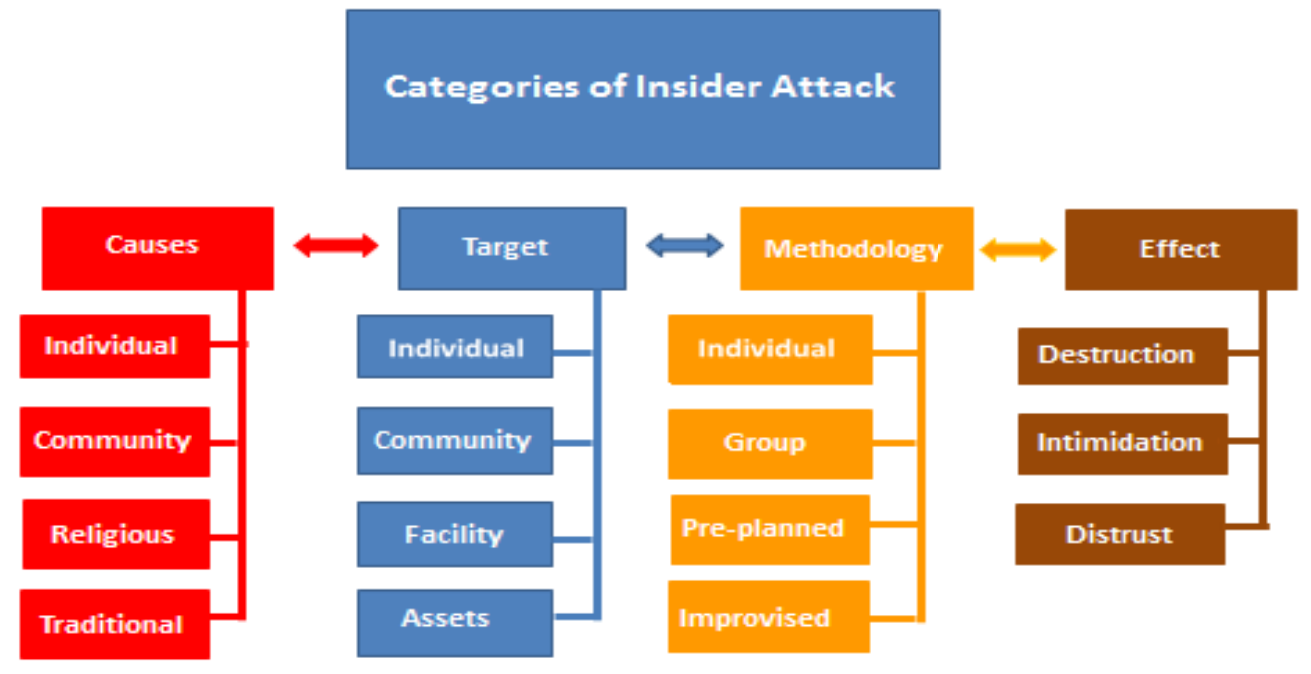

Figure no. 3: Categories of insider attacks

(Source: Authors)

One of the most sensitive areas is harm made to religious matters, which can be either presumed or real. In peace operations, inadequate levels of local knowledge can often result in violations of local religious customs, rituals, and people's sensitivities. Economic and supply-related difficulties in a given area can very quickly transform into religious conflicts, especially in the case of operations involving communities of different religions. In such cases, religious extremism can rapidly develop. The hostile party quickly finds people with deep religious orientation who can be used for attacks.

Traditional causes also emerge if there are operational forces that have already confronted the population in the area of operations in several cases in history, or if some members of the operational forces have a deep emotional attachment to local society (Horváth, 2016).

When examining the targets of insider attacks, the most typical ones are individual targets. In attacks against such people the attackers are usually persons from their immediate environment. The target persons are often identified with a political course or idea, or are charismatic key leaders of a unit or operation, or of the supported democratic leadership.

Attacks can be aimed at groups, communities, or operational forces when some common mission is being executed and the attacker - who is often a suicide bomber - is a member of the target group.

An insider attack can take place also against a facility that is dominant in that area or in the life of the country. Facilities serving critical infrastructure typically have strong physical protection against external attacks, however, an inside attacker, knowing security policies or a part of those, has the opportunity to enter an object and carry out the attack there.

In peacekeeping operations, a target may be designated for an insider attack, which is an instrument that plays a decisive role and significance in the operations. These can be precision weapons, control devices, guidance systems, computers, or unmanned aerial vehicles (UAVs), which are increasingly used today. The destruction of these devices, or even just damaging them can be a serious drawback in conducting operations.

In terms of attack methods, individual attacks are the most common and they are 
the most difficult to detect. Usually, such an attacker has no helpers, no associates, the attack is often carried out on an ad-hoc basis, exploiting some situation. The perpetrator's act is often characterized by the principle of "opportunity makes the thief", it is triggered by a momentary agitation or immediate harm. Most of the time, there is no preparation for such an attack.

The execution of group attacks already requires some organization and preparation, therefore their detection can be more effective than that of individual attacks. On the other hand, a coordinated attack of greater strength typical inflicts more injured and wounded. An insider group attack can also be a form of asymmetric warfare, as well as a preparation for a coordinated external armed attack.

In the case of a prepared attack, the selection of the target is deliberating, wellconsidered, and requires some impact analysis from the attacker. Prepared attacks, especially group attacks, are easier to detect due to the relating organizational tasks.

According to the authors, most of the improvised attacks take place because of emotional reasons, by taking advantage of the situation and opportunity, and it is the most difficult to detect and predict.

Examining the insider attacks, the result to be achieved can be the destruction of the target or targets, which is characteristic mostly in the case of individual targets, however, it can also be true for an attack on less secured (protected, defended) stationary objects or facilities. In an impact assessment, it should never be forgotten that, although it is not common, the elimination of an important person can also be a priority in terms of impact. Leaders must not forget that perfect protection never has existed, and this is increasingly true of regulations to prevent insider attacks.

A fundamental objective of attacks can be intimidation, when the destruction of the selected target is not an expected effect, it is rather a message to the forces, organizations, and masses supporting the peace operation, or possibly the generation of some kind of disturbance as a secondary effect.

One of the effects of insider attacks could be the creation of distrust towards the peacekeeping forces, or the generation of disturbances and confusion, sometimes mass hysteria, which may be the preparation of a coordinated armed attack against government or peacekeeping forces. Such an attack can be not only a physical one, but also, in some cases, a deliberately executed spread of rumours and fake news from undercover individuals. Another impact could be the development of a high level of distrust towards each other in the ranks of democratic forces, thus reducing the effectiveness of counterinsurgency actions and operations.

The third effect of attacks is actual physical destruction, devastation, in which case the attacker tries to use devices that increase the impact of destruction (for example, a suicide attacker wearing an explosive belt).

\section{Basic Issues of Protection against Insider Threats and Attacks}

Protection against insider attacks is extremely difficult due to the complexity of the attacks, nevertheless all precautions must be made to prevent them and reduce their impacts (Böcz, 2014).

The most important defence method to prevent insider attacks is intelligence and preparation. Prevention must include the application of all types of intelligence, and then the verified information should be delivered to the potential target as fast as possible, while simultaneous and immediate countermeasures must be issued. During intelligence operations, the main emphasis should be on prevention, however, this fact should remain hidden from the potential attacker. Covert information gathering and intelligence analysis play a prominent role in the conduct of investigation. 


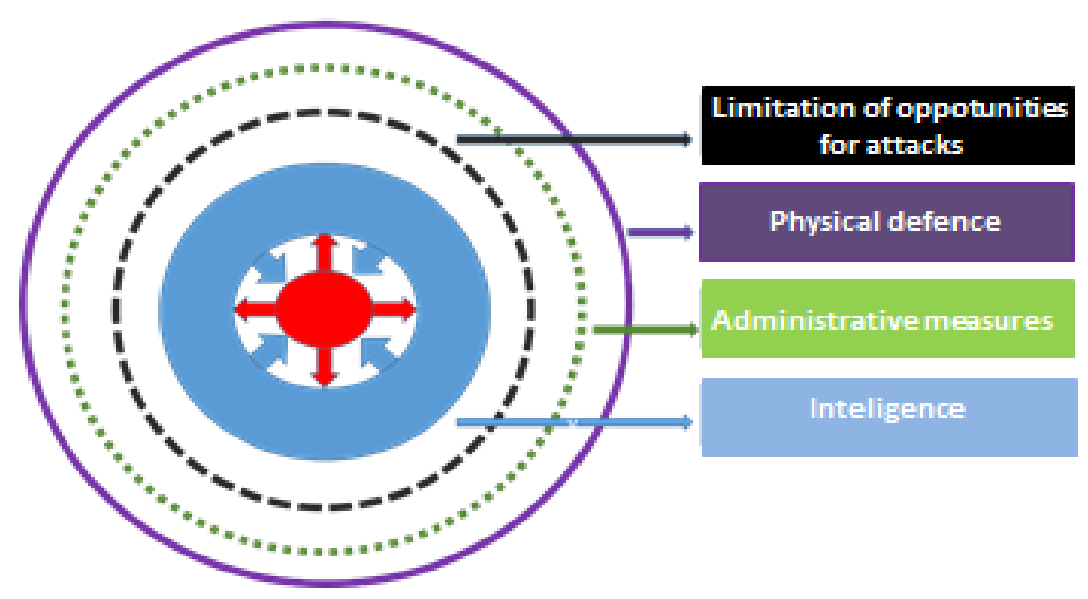

Figure no. 4: "Four-zone protection" against insider attacks

(Source: Authors)

Preventive methodology includes the development of administrative rules and their enforcement both at leadership- and execution-level personnel. These measures include, for example, the restriction of access to the protected facility, security checks and screenings before a person is selected for or appointed into a position. It is a common rule that in a protected object only the use of tools and equipment commissioned there is allowed. This includes the requirement that during their missions, the deployed teams and sub-units - if possible - should be homogeneous both in terms of nationality and religious affiliation.

Physical protective measures can be divided into two main categories: the use of personal protective equipment, and the protection provided by collective tools. Their use is in the interest of each individual, but the enforcement of their use is the responsibility of the commander or the leader.

Limiting attack opportunities is a complex activity aimed at fending off, but most importantly, preventing insider attacks. Insider attacks can be characterised with three types of features: surprise, speed, and shock.

Knowing these features, we can reduce surprise with fast analyses, continuous data collection, and an operating and alert system. Speed can be reduced by following and controlling administrative rules. The shock caused by an insider attack can be reduced through well-planned preparation, the psychological selection of personnel for peace operations, and ongoing processing of the lessons learned. Experience has shown that procedures and preparations against insider attacks are a priority for leader.

\section{Conclusions}

In the opinion of the authors, it is impossible to clearly identify the causes of an insider attack. Those causes leading to an insider attack are complex, and their identification requires a great deal of attention.

The question arises as to what can be done in order to reduce or possibly avoid such events:

- The role of media and mass communication in the acceptance of peace operations and in gaining the support of the local population is of paramount importance;

- It is very important to establish personal contacts between trainers and trainees during the preparation of the government forces of new democracies; 
- It is necessary for the mentors and trainers to have a high degree of cultural and religious knowledge of the population in the area of operations;

- Continuous review of training, pedagogical methodologies, and effectiveness during the training programs;

- Acceptance of national specificities and impartiality in various national and ethnic issues;

- In the course of joint implementation of tasks, it is necessary to clearly demarcate missions with the government forces of the new democratic state;

- Minimizing the material and human losses of the civilian population during the execution of peace operations;
- Appropriate and continuous evaluation and analysis of the operational environment;

- Well-targeted preparation of peacekeeping forces for their mission;

- Reduction of the opportunity of attacks by the introduction of and adherence to active and passive protective measures.

In the opinion of the authors, these are the key issues that, if kept in focus, provide a chance to reduce or even minimize insider attacks. Today, a number of studies and recommendations have been made to protect the service members of armed forces involved in peacekeeping missions, however, they are only effective if they are adhered to, and required to be adhered to.

\section{REFERENCES}

Böcz, L. (2014). The Tasks of a Staff in Military Decision Making and the Execution of Military Operations. Budapest: National University of Public Service.

Fukuyama, F. (2005). State-Building: Governance and World Order in the $21^{\text {st }}$ Century. Budapest, ISBN: 9637340122.

Horváth, T. (2014). The Structure, Staff, and Operation of ISAF Regional Command North. In Boldizsár, G., \& Wagner, P. (Eds), (pp. 67-72). Budapest: National University of Public Service.

Horváth, T. (2016). Some Challenges of Engineer Support to Operational Environment. In Csengeri, J., \& Krajnc, Z. (Eds), (pp. 234-274). Budapest: National University of Public Service.

Horváth, T. (2019). Emergency Cases at Countering Improvised Explosive Devices, and their Potential Management. Revista Academiei Forțelor Terestre, Vol. XXIV, Issue 2 (94), 95-106.

Komjáthy, L. (2016). The Preparation of Effect-based Operations during Counterinsurgency Operations. Military Review, Vol. 144, Issue 3, 64-74, Budapest.

Komjáthy, L. (2017a). The Nature and History of Cooperation of Military and Police Members and their Tasks during Crisis Management. Military Science Review, Vol. X, Issue 2, 193-206, Budapest.

Komjáthy, L. (2017b). Training of Experiences, Method and Peculiarities of the Training of Law Enforcement Organizations of Young Democratic States During in Peace Operations. Military Science Review, Vol. X, Issue 4, 98-111, Budapest.

Scarrow, S. (2019). 21 Best-Known Quatations from Simon Scarrow, available at: https://www.citatum.hu/szerzo/Simon_Scarrow, accessed on 31 January 2019.

Schmidt, I. (2013). Insider Threat. Lessons of Insider Threat Learned in Afghanistan. Military Science Review, Vol. 5, Budapest. 